\title{
Assessing the Cumulative Effect of Service Errors on Customer Perceptions
}

\author{
Rhonda L. Hensley, Joanne S. Utley \\ Department of Management, College of Business and Economics, North Carolina A\&T State University, Greensboro, USA \\ Email: hensleyr@ncat.edu
}

How to cite this paper: Hensley, R.L. and Utley, J.S. (2019) Assessing the Cumulative Effect of Service Errors on Customer Perceptions. Journal of Service Science and Management, 12, 521-530. https://doi.org/10.4236/jssm.2019.124035

Received: May 11, 2019

Accepted: June 18, 2019

Published: June 21, 2019

Copyright $\odot 2019$ by author(s) and Scientific Research Publishing Inc. This work is licensed under the Creative Commons Attribution International License (CC BY 4.0).

http://creativecommons.org/licenses/by/4.0/

\section{cc) (i) Open Access}

\begin{abstract}
To decrease the possibility of customer defections, service managers need to track the cumulative effect of service errors on customer perceptions. Despite this need, past research in the service management literature does not provide managers with comprehensive methodologies tailored to this problem. Most previous research views service error as either a technical issue which can be addressed via reliability tools commonly used in manufacturing or as a dimension of service quality which can be assessed via customer feedback a single point in time. This paper will integrate concepts from both of these approaches to propose a methodology for analyzing the cumulative effect of service errors on customer perceptions. The methodology will also include a framework for classifying service error.
\end{abstract}

\section{Keywords}

Service Errors, Failure Analysis, Service Reliability

\section{Introduction}

Service reliability may be defined as the firm's ability to provide a specific service without the need to correct for service errors [1] [2] [3] [4]. This ability is essential for a successful service operation. Not only is reliability one of the most influential components of service quality [3] [5], past research has linked reliability improvement to greater customer loyalty and higher customer retention rates [6] [7] [8].

In practice, every service-even one that is usually reliable-experiences some type of service failure sooner or later. If a customer feels that service was very reliable prior to the failure then that customer may view the service failure as an anomaly and remain confident about the service provider [9]. However, if the customer's prior history with the company includes several episodes of unrelia- 
ble service, then the customer may not be as likely to dismiss the current reliability failure. In the worst case, the effect of repeated service errors can shake the customer's confidence with the service to such a degree that the customer decides to defect to a competitor.

To reduce the possibility of customer defections, service managers should try to understand the ramifications of every lapse in service reliability, even the seemingly minor ones. In addition, managers need to track the cumulative effect that service errors have to determine if the customer is approaching the "point of no return" at which the customer defects. Despite this need, the service management literature does not provide managers with comprehensive methodologies tailored to this specific issue. Most previous research in the service management literature has examined reliability from one of two very different perspectives $(1984,1985,1988,1995,1999,2002,2004,2005,2010)$. The first approach addresses reliability via analytical tools which originated in the manufacturing sector. Thus, its focus is technical. The second approach views reliability as a service quality dimension that can be assessed at a particular point in time via customer feedback. This approach utilizes a customer perception focus. Neither approach is by itself complete. This paper will integrate concepts from both perspectives to propose a methodology for analyzing the cumulative effect of service error on customer perceptions. This approach is unique because it combines both approaches to produce a more complete method that managers might find useful.

This paper is organized as follows. Section 2 will summarize key technical tools and customer focused methods applicable to service reliability. Section 3 will draw on these tools and methods to develop a methodology for analyzing the cumulative effect of service failure on customer perceptions. Section 4 discusses the managerial implications of the methodology and possible avenues for future research.

\section{Literature Review}

Review of the service management literature reveals that there are two fundamental approaches to analyzing service reliability. The first approach involves the application of one or more reliability tools commonly used in manufacturing operations to measure or prevent errors. The second approach utilizes one or more methods for capturing customer perceptions of service quality. Both approaches furnish valuable insight on the issue of service reliability.

\subsection{Summary of Technical Methods}

In general, technical reliability tools provide insight on service error in three fundamental ways: 1) they underscore the importance of counting the number of failures in service delivery; 2) they illustrate that a customer may experience a number failure points in service delivery and 3) they reveal that the effect of service errors is cumulative. 
Failure rate analysis represents a useful tool for counting service errors. In their application of failure rate analysis at a university office, Gunes and Devici [10] modeled service reliability as a function of the total count of weighted errors at a single stage. They argued that due to the non-continuous nature of many service operations, the number of errors is more relevant to service reliability analysis than the timing of the errors. Gunawardane [9] later extended the Gunes and Deveci [10] model of error rate analysis to a multi-stage service process.

In devising this extension, Gunawardane [9] noted that a process perspective of service reliability must be utilized to capture the complexity of service delivery. The process perspective views service delivery as a series of stages - rather than as a single stage [11] [12] [13] [14]. Shostack [15] also argued that process flow must be analyzed to ensure error free service and developed the concept of service blueprinting for mapping all processes that comprise the service. Service blueprinting is valuable because it allows the service provider to visualize the entire service delivery process, thereby emphasizing that reliability requires system wide analysis [15] [16] [17] [18]. Similarly, the customer journey approach also utilizes a system wide view by mapping service delivery from the customer's perspective [19] [20]. This mapping can provide valuable information for understanding customer perceptions and feelings about the service experience [20] [21].

Analysis of a service system's architecture provides yet another system-wide approach to reliability. Service systems may be examined by understanding their design and the interdependencies between apparently disparate parts of the service delivery process [22]. Sun et al. [23] noted that combinations of series, parallel and various hybrid designs form the basis for a systems view of error [22].

Since each stage in a service process is potentially a point of service failure, the reliability of each stage must be incorporated into a model of overall service reliability. If a customer experiences several service errors while moving from stage to stage, the combination of multiple errors can produce a "snowball" effect that can lead catastrophic consequences [17] [22] [23] [24]. Likewise, if a customer has experienced a series of services errors over several visits to a service, the cumulative effect of these bad experiences will tend to worsen as the number of bad service encounters increases. At some point, the long term or cumulative effect of unreliable service may drive the customer away.

The literature shows that failsafe techniques constitute a proactive method for reducing service errors [17] [24] [25]. Unlike statistical process control methods which involve quantitative analysis of a large volume of data, failsafe techniques utilize information flows within the service process, performance standards and worker empowerment to prevent service errors [17] [26].

\subsection{Summary of Customer-Focused Methods}

In contrast to technical reliability tools, customer focused methods analyze customers' perceptions of service reliability. Customer perceptions may be gathered 
using surveys, content analysis or other feedback mechanisms.

The SERVQUAL survey was the first to address the issue of service reliability from the customer's perspective. The survey was based on a model for consumer perceived service quality which included a five-item reliability measure [4] [27]. The five items in the reliability scale were "1) providing services as promised;2) dependability in handling customer service problems; 3) performing services right the first time; 4) providing services at the promised time; and 5) maintaining error-free records" ([9], p. 586). Many researchers have incorporated these SERQUAL reliability items in their own questionnaires. Customer survey methods provide insight on service errors in two ways. First, they model reliability as a construct composed of several factors that can affect the customer's perception of service error. Second, they help to reveal the degree of customer satisfaction or dissatisfaction that exists for each of the factors and thus enable a service manager to identify which factors could be negatively affecting customers' perceptions of errors.

Content analysis of customer complaints, especially in open-ended questions, is an important tool for examining service errors and gaining an understanding of the customer's perspective on them [28]. Immediate analysis of customer complaints can provide "early warning of impending performance deterioration" ([28], p. 478). The process of content analysis begins with a trial sort of the criticisms into categories [29]. This is followed by a second sort by experts guided by a list of categories with examples of comments corresponding to each category [29] [30]. Interrater reliability is computed to determine if it is sufficiently high [29] [30] [31] [32]. If not the sort process repeats [29] [31].

Although both technical reliability tools and customer focused methods offer valuable insight on service errors, they do so from different perspectives, utilize different analytical methods and provide different types of information to the manager. The technical approach to reliability underscores the importance of the cumulative effect of service failures over time; however, this approach does not capture the customer's perceptions of service error. In contrast, customer focused methods help reveal customer perceptions of reliability at a point in time but fail to address the cumulative effect of service failure over time. Thus, each approach, taken separately, provides only a partial perspective of service error. Needed is a methodology to integrate both approaches so that a more comprehensive view of service error can be developed. The following section will propose such a methodology.

\section{Methodology}

The preceding discussion illustrates that any method that integrates the technical and the customer-based approaches to service reliability must include the following features: 1) it utilizes a systems approach, 2) it counts the number of service errors customers experience over time, 3 ) it gathers customer feedback on actual service failures customers experienced, 4) it helps the manager gauge the 
effect of each of these individual service errors, and 5) it helps the manager assess the cumulative effect of service errors over time.

There are three basic steps to achieving a methodology that incorporates these five features:

Step 1: Understand the system.

Step 2: Count and analyze the individual service errors that customers actually experienced.

Step 3: Assess the cumulative effect of the service errors over time.

To understand the system, the manager can utilize any of the process mapping tools discussed earlier. The manager can use these tools to anticipate possible service fail points before an error occurs.

To count and understand individual service errors, the manager needs a customer feedback system on service errors and a method for assessing the nature of an error. The manager needs to adopt a process for monitoring customer complaints about real events in the service environment. In addition, the manager must use the customer's perceptions in interpreting service errors. To give a manager this needed insight, it is useful to classify reliability failures along two dimensions. The first dimension involves the perceived severity of the individual service failure. The second dimension deals with responsibility for the reliability failure.

Severity of service failures may be defined as the "magnitude of loss that customers experience due to the failure" ([32], p. 132). Various studies have developed measures for severity of service failures usually ranging from minor to major [33] [34] [35]. In this study severity of service failure is defined as either minor or severe using the model proposed by Hoffman, et al. [34]. A minor failure is one that may cause delays or changes to the service but which can be corrected and allow the service to continue to completion. A major failure is one that prevents the service from being completed or results in a negative conclusion on the part of the customer.

Some service failures result from employees' errors while others stem from customers' mistakes [25]. Since the service failures themselves can range from minor to severe, four possible combinations of failure severity and responsibility may occur in practice. These include: 1) minor failures for which the customer is to blame, 2) major failures for which the customer is responsible, 3) minor failures for which the provider is to blame, and 4) major failures for which the provider is responsible. Figure 1 summarizes these four possible combinations.

Each type of failure classified in Figure 1 affects customer perception in different ways. Obviously, severe errors made by service workers will have a greater impact on customer perceptions than will minor worker mistakes. In contrast, interpretation of the effect of customer error is not as straightforward. When a service reliability failure occurs, the customer frequently blames the service provider for causing it [36] [37], even if the customer is actually responsible for the problem-particularly when rule based errors occur. A customer makes a rule based error when he or she incorrectly applies familiar scripts or responses to a 


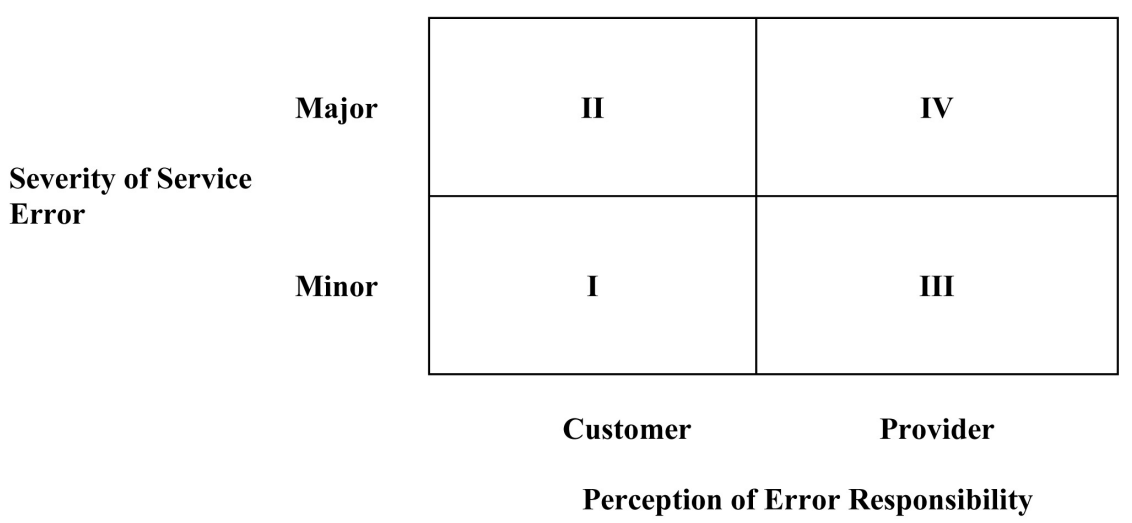

Figure 1. Service error framework.

service situation [36]. For instance, a restaurant customer may incorrectly assume that a waitress will collect the payment for the bill at the table and then discover that he must pay for his meal at the register. Even though the customer made the mistake, he will blame the waitress for the inconvenience.

After a service failure, the manager could use Figure 1 as a starting point for rating its impact on customer perceptions. This impact is a function of incident severity and responsibility for its occurrence:

$$
I_{i}=f\left(S_{i}, R_{i}\right)
$$

where: $I_{i}=$ the impact of the $I^{\text {th }}$ incident on customer perceptions;

$S_{i}=$ customer perception of the severity of the $I^{\text {th }}$ incident;

$R_{i}=$ customer perception of who is responsible for the $I^{\text {th }}$ incident.

To assess the cumulative effect of a series of $\mathrm{n}$ consecutive service errors, the manager can simply total the individual impact ratings $I_{i}$.

$$
C_{n}=\sum_{i=1}^{n}\left(I_{i}\right)
$$

where: $C_{n}=$ the cumulative impact of the n consecutive incidents of service error;

$I_{i}=$ the impact of the $I^{\text {th }}$ incident on customer perceptions.

Figure 2 presents a graphical method for representing the cumulative impact function. While this graph can be used to depict the cumulative effect of service errors during a single service encounter, it is especially useful as a tool for longitudinal analysis of service failures. When used this way, the cumulative effect of service failure is a monotonically increasing function of the total number of customer perceived service errors over a series of past service encounters. Thus, with each successive failure, the perceived unreliability of the service either increases or, at best, remains at the same level.

\section{Discussion}

This paper has argued that the customer's perspective of service reliability must be integrated with a longitudinal, technical approach to reliability analysis. To achieve this sort of integration, the service manager first must consider what type of data to collect and then how to organize and interpret the data so that the 


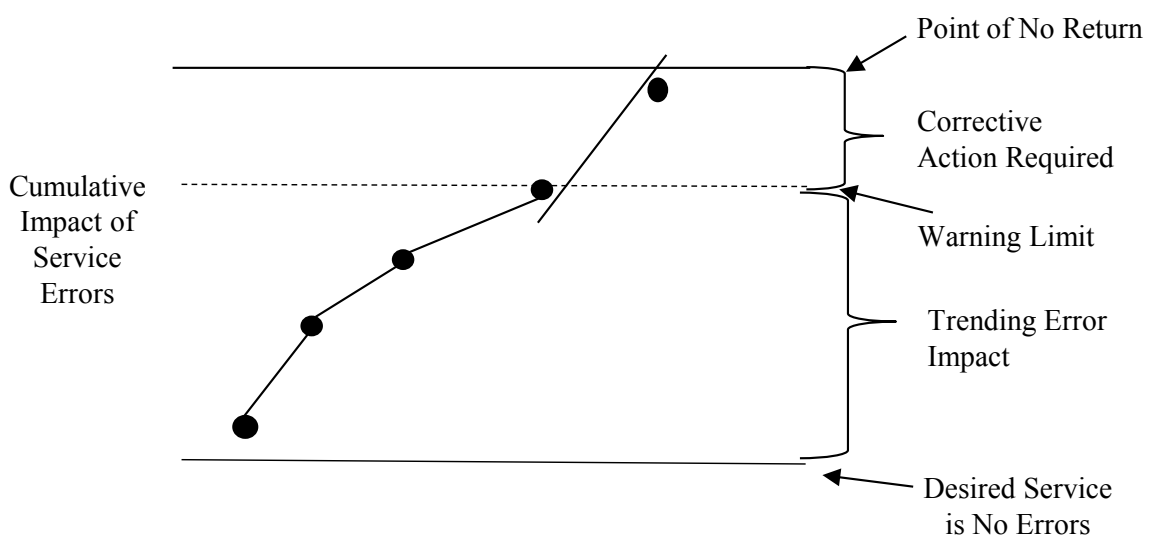

Figure 2. Relative impact of consecutive errors in service provisions.

possibility of future customer defections due to reliability failures can be reduced.

Improved data collection is the starting point for improved reliability analysis. A fundamental managerial implication of this paper is that the service manager cannot simply use a few Likert scaled items to gauge the cumulative effect of poor reliability on customer perceptions. Instead of adopting this rather limited "snap shot" approach, the manager could use open ended survey questions to obtain information about the specific reliability failure a customer has experienced. It is important to ask the customer such questions as: "How serious was this service failure to you?" and "Whose fault was it and why?" A customer's responses to these types of open-ended questions help the manager gauge the impact of the individual service failure.

The manager might get an even better idea of the error impact by following up directly with the customer. For instance, suppose in a full-service restaurant a customer arrives and her name is added to the waitlist for a seat. After other customers appear to be seated ahead of her, she becomes concerned, approaches the host and demands to see the manager. If she is in a hurry this might be a major error but if the manager explains that her name was called several times and she did not hear then she might reconsider who is responsible for the error. The change in her perceptions will lower the negative impact of the error.

Service errors should be tracked during the course of business. The manager might want to use Pareto analysis to determine the relative frequency of the different types of service errors. This sort of approach will help the manager frame suitable failsafe techniques to prevent mistakes from occurring in the first place. Obviously, the failsafe techniques must be tailored to the type of error that can occur. In particular, the manager must consider how to help his customers avoid the various rule-based errors they make since the customer will blame the service rather than themselves for these errors.

Since the types of rule based errors a customer makes will vary with the service context, future research could include applications of this approach in several service settings. In each of these settings, it would be interesting to investi- 
gate the relative impact of customer error on perceived reliability compared to the effect of worker based error. In addition, customer data from these actual service contexts could be used to examine the various patterns through which the cumulative effect emerges.

\section{Conclusion}

In summary, the methodology proposed in this study represents only an initial step in the investigation of the cumulative effect of reliability failure on customer perceptions. However, the proposed methodology does help the manager view reliability as a service feature that must be tracked and managed over time. Such a perspective can potentially reduce customer defections due to unreliable service.

\section{Conflicts of Interest}

The authors declare no conflicts of interest regarding the publication of this paper.

\section{References}

[1] Galetzka, M., Verhoeven, J.W.M. and Pruyn, A. (2006) Service Validity and Service Reliability of Search Experience and Credence Services: A Scenario Study. International Journal of Service Industry Management, 17, 271-283.

https://doi.org/10.1108/09564230610667113

[2] Van Raaij, W.F. and Pruyn, A. (1998) Customer Control and Evaluation of Service Validity and Reliability. Psychology \& Marketing, 15, 811-832. https://doi.org/10.1002/(SICI)1520-6793(199812)15:8<811::AID-MAR6>3.0.CO;2-8

[3] Caruana, A. and Pitt, L.F. (1997) Right First Time in Service: A Checklist of Best Practice and the Link to Performance. Journal of Services Marketing, 11, 366-374. https://doi.org/10.1108/08876049710187473

[4] Parasuraman, A., Zeithaml, V.A. and Berry, L.L. (1985) A Conceptual Model of Service Quality and Its Implications for Future Research. Journal of Marketing, 49, 41-50. https://doi.org/10.1177/002224298504900403

[5] Madu, C.N. (1999) Reliability and Quality Interface. International Journal of Quality \& Reliability Management, 16, 691-698. https://doi.org/10.1108/02656719910286198

[6] Kandampully, J. (1998) Service Quality to Service Loyalty: A Relationship Which Goes beyond Customer Services. Total Quality Management, 9, 431-443. https://doi.org/10.1080/0954412988370

[7] Dabholkar, P.A., Shepherd, C.D. and Thorpe, D.I. (2000) A Comprehensive Framework for Service Quality: An Investigation of Critical Conceptual and Measurement Issues through a Longitudinal Study. Journal of Retailing, 76, 139-173. https://doi.org/10.1016/S0022-4359(00)00029-4

[8] Hume, M. (2008) Understanding Core and Peripheral Service Quality in Customer Repurchase of the Performing Arts. Managing Service Quality, 18, 349-369. https://doi.org/10.1108/09604520810885608

[9] Gunawardane, G. (2004) Measuring Reliability of Service Systems Using Failure Rates: Variations and Extensions. International Journal of Quality \& Reliability 
Management, 21, 578-590. https://doi.org/10.1108/02656710410536581

[10] Gunes, M. and Deveci, I. (2002) Reliability of Service Systems and an Application in Student Office. International Journal of Quality \& Reliability Management, 19, 206-211. https://doi.org/10.1108/02656710210413525

[11] Armstrong, P.K. (1995) A Model for Analyzing Quality in the Service Delivery Process. In: Harker, P., Ed., The Service Productivity and Quality Challenge, Dordrecht, Kluwer Academic Publishers, The Netherlands, 311-342. https://doi.org/10.1007/978-94-011-0073-1_12

[12] Souteriou, A.C. and Hadjinicola, G.C. (1999) Resource Allocation to Improve Service Quality Perceptions in Multistage Service Systems. Production and Operations Management, 8, 221-239. https://doi.org/10.1111/j.1937-5956.1999.tb00306.x

[13] Sulek, J.M. (2004) Statistical Quality Control in Services. International Journal of Service Technology and Management, 5, 522-531.

[14] Sulek, J.M., Marucheck, A. and Lind, M.R. (2005) Measuring Performance in Multi-Stage Service Operations: An Application of Cause Selecting Control Charts. Journal of Operations Management, 24, 711-727. https://doi.org/10.1016/j.jom.2005.04.003

[15] Shostack, G.L. (1984) Designing Services That Deliver. Harvard Business Review, 62, 133-139.

[16] Zine, P.U., Kulkarni, M.S., Ray, A.K. and Chawla, R. (2016) Designing Flexible Service Systems: Application to Machine Tools. Journal of Intelligent Manufacturing, 27, 1237-1259. https://doi.org/10.1007/s10845-014-0947-y

[17] Sukek, J.M. and Lind, M.R. (2005) Fail-Safe Methods for Paratransit Safety. Journal of Public Transportation, 8, 65-85. https://doi.org/10.5038/2375-0901.8.4.5

[18] Chase, R.B. and Bowen, D.E. (1991) Service Quality and the Service Delivery System. In: Brown, S.W., Gummersson, E., Edvardsson, B. and Gustavasson, B., Eds., Service Quality: Multi-Disciplinary and Multi-National Perspectives, Lexington Books, Lanham, MD, 157-178.

[19] Zomerdijk, L.G. and Voss, C.A. (2010) Service Design for Experience-Centric Services. Journal of Service Research, 13, 67-82. https://doi.org/10.1177/1094670509351960

[20] Halvorsrud, R., Kvale, K. and Følstad, A. (2016) Improving Service Quality through Customer Journey Analysis. Journal of Service Theory and Practice, 26, 840-867. https://doi.org/10.1108/JSTP-05-2015-0111

[21] Følstad, A. and Kvale, K. (2018) Customer Journeys: A Systematic Literature Review. Journal of Service Theory and Practice, 28, 196-227. https://doi.org/10.1108/JSTP-11-2014-0261

[22] Hensley, R.L. and Utley, J.S. (2011) Using Reliability Tools in Service Operations. International Journal of Quality \& Reliability Management, 28, 587-598. https://doi.org/10.1108/02656711111132599

[23] Sun, J., Xi, L., Du, S. and Ju, B. (2008) Reliability Modeling and Analysis of Serial-Parallel Hybrid Multi-Operational Manufacturing System Considering Dimensional Quality, Tool Degradation and System Configuration. International Journal of Production Economics, 114, 149-164. https://doi.org/10.1016/j.ijpe.2008.01.002

[24] Perrow, C. (1984) Normal Accidents: Living with High-Risk Technologies. Basic Books, New York.

[25] Chase, R.B. and Stewart, D.M. (1994) Make Your Service Fail-Safe. Sloan Management Review, 35, 35-44. 
[26] Harvey, J. (1998) Service Quality: A Tutorial. Journal of Operations Management, 16, 583-597. https://doi.org/10.1016/S0272-6963(97)00026-0

[27] Parasuraman, A., Zeithaml, V.A. and Berry, L.L. (1988) SERVQUAL: A Multiple-Item Scale for Measuring Consumer Perceptions of Service Quality. Journal of Retailing, 64, 12-40.

[28] Sulek, J.M. and Hensley, R.L. (2010) Updating Service Operations. Managing Service Quality: An International Journal, 20, 475-489. https://doi.org/10.1108/09604521011073759

[29] Krippendorff, K. (1980) Content Analysis: An Introduction to Its Methodology. Sage Publications, Thousand Oaks, CA.

[30] Duriau, V.J., Reger, R.K. and Pfaffer, M.D. (2007) A Content Analysis of the Content Analysis Literature in Organizational Studies. Organizational Research Methods, 10, 5-34. https://doi.org/10.1177/1094428106289252

[31] Mir, S., Lu, S.-H., Cantor, D. and Hofer, C. (2018) Content Analysis in SCM Research: Past Uses and Future Research Opportunities. The International Journal of Logistics Management, 29, 132-190. https://doi.org/10.1108/IJLM-09-2016-0200

[32] Neuendorf, K.A. (2002) The Content Analysis Guidebook. Sage, Thousand Oaks, CA.

[33] Hess, R.L., Ganesan, S. and Klein, N.M. (2003) Service Failure and Recovery: The Impact of Relationship Factors on Customer Satisfaction. Journal of the Academy of Marketing Science, 31, 127-145. https://doi.org/10.1177/0092070302250898

[34] Hoffman, K.D., Kelley, S.W. and Rotalsky, H.M. (1995) Tracking Service Failures and Employee Recovery Efforts. Journal of Services Marketing, 9, 49-61. https://doi.org/10.1108/08876049510086017

[35] Craighead, C.W., Karwan, K.R. and Miller, J.L. (2004) The Effects of Severity of Failure and Customer Loyalty on Service Recovery Strategies. Production and Operations Management, 13, 307-321. https://doi.org/10.1111/j.1937-5956.2004.tb00220.x

[36] Stewart, D.M. and Chase, R.B. (1999) The Impact of Human Error on Delivering Service Quality. Production and Operations Management, 8, 240-263. https://doi.org/10.1111/j.1937-5956.1999.tb00307.x

[37] Miller, D. and Porter, C. (1998) Errors and Biases in the Attribution Processes. In: Abramson, L., Ed., Social Cognition and Clinical Psychology, Guilford Press, New York. 